цитоплазматическая ЛДГ увеличилась с 422,73 до 526,8 Ед/л, трасаминаза АЛТ показала изменения с 42,1 до 67,9 Ед/л, в то время как уровень АСТ практически не изменился ( с 40,0 до 39,9 Ед/л). На фоне лечения наблюдалось уменьшение концентрации СРБ с 47,2 до 33,6 мг/л, что позволяет нам говорить о снижении риска развития цитокинового шторма и об эффективной терапии в лечении COVID - 19.

1. Шамхалова М.Ш., Мокрышева Н.Г., Шестакова M.В., «COVID-19 И ПОЧКИ»// Национальный медицинский исследовательский центр эндокринологии, Россия г. Москва.

2. Семенова Д.С. [Электронный ресурс] - 2019-URL: https://btfr.cc/tei (Дата обращения 28.05.2021). Текст электронный.

3. Лактатдегидрогиназа [Электронный $\quad$ ресурс] https://biokhimija.ru/enzymes/lactatdg.html (Дата обращения 28.05.2021). Текст электронный.

4. Лабораторная служба HELIX [Электронный ресурс] - 2021 - URL: https://helix.ru/kb/item/06-010 (Дата обращения 28.05.2021). Текст электронный.

5. Медицинский вестник [Электронный ресурс] - 2021- URL: https://medvestnik.by/konspektvracha/izmenenie-laboratornykh-pokazatelej-pri-covid-19 (Дата обращения 28.05.2021). Текст электронный.

6. Лабораторная служба INVITRO [Электронный ресурс] - 2021 - URL: https://www.invitro.ru/library/labdiagnostika/24506/ (Дата обращения 28.05.2021). Текст электронный

7. Всемирная организация здравоохранения [Электронный ресурс] - 2020 -URL: https://www.euro.who.int/ru/health-topics/health-emergencies/pages/news/news/2020/03/whoannounces-covid-19-outbreak-a-pandemic (Дата обращения 28.05.2021). Текст электронный

\title{
Савостьянова T.A. \\ Контролируемые системы доставки на основе полимерных 3D-скаффолдов, полученных методом электроспиннинга
}

Новосибирский государственный университет (Россия, Новосибирск)

doi: $10.18411 / \mathrm{j}-07-2021-02$

\section{Аннотация}

В статье рассматривается получение биосовместимых полимерных 3Dскаффолдов с помощью технологии электроспиннинга и их применение в качестве систем для контролируемой доставки различных биоактивных агентов. Описываются трансдермальные, быстрорастворимые, «интеллектуальные» и имплантируемые системы доставки на основе полимерных скаффолдов и дается оценка их перспективности в качестве материалов для областей контролируемой доставки биоактивных агентов и регенеративной медицины.

Ключевые слова: электроспиннинг, полимерные 3D-скаффолды, системы для контролируемой доставки, программируемое высвобождение препаратов.

\section{Abstract}

The article discusses the production of biocompatible polymer $3 \mathrm{D}$ scaffolds using electrospinning technology and their application as systems for the controlled delivery of various bioactive agents. Transdermal, rapidly dissolving, "intelligent" and implantable delivery systems based on polymer scaffolds are described and their prospects as materials for controlled delivery of bioactive agents and regenerative medicine are evaluated.

Keywords: electrospinning, polymer 3D-scaffolds, controlled delivery systems, programmed drug release.

В настоящее время в медицине растет актуальность применения таргетных и контролируемых систем доставки биологически активных молекул. В частности, 
особый интерес направлен на создание липосом, полимерных частиц и гидрогелей, включающих как низкомолекулярные вещества с противораковой, иммуномодуляторной, бактерицидной активностью, так и высокомолекулярные, в том числе, факторы роста, хемоаттрактанты, пептиды, ДНК, siРНК. Основной целью применения контролируемых систем доставки является улучшение фармакокинетических свойств препаратов, предотвращение их побочных эффектов и усиление терапевтической эффективности, достигаемое нацеливанием препарата на орган-мишень.

Для реализации перечисленных выше задач создание полимерных микро- и нановолокон методом электроспиннинга представляет альтернативный способ, активно набирающий популярность последнее десятилетие. Полученные с помощью данной технологии скаффолды обладают рядом преимуществ для биомедицинского применения, в том числе сходством с внеклеточным матриксом, высоким отношением площади поверхности к объему, механической гибкостью. Метод электроспиннинга позволяет успешно включать в получаемые материалы различные типы активных веществ от небольших молекул до ДНК и белков. Системы доставки на основе полимерных волокон демонстрируют высокую способность к загрузке лекарственных средств и их контролируемое высвобождение [1-4].

\section{Технология электроспиннинга}

Электроспиннинг (ЭС) представляет собой технологию получения трехмерных материалов с волокнистой внутренней структурой из ультратонких нитей полимера, образующихся при действии на раствор полимера электрического поля. Установка для электроспиннинга (рис.1) состоит из источника высокого напряжения (для заряда раствора полимера), заземленного коллектора и шприцевого насоса (для подачи раствора полимера) с тонкой затупленной иглой-капилляром. Когда под действием внешнего напряжения на конце капилляра на границе раздела фаз воздух-раствор полимера накапливается достаточный отталкивающий заряд и сила отталкивания становится равна поверхностному натяжению, поверхность раствора начинает формировать конус Тейлора.

При дальнейшем увеличении прикладываемого напряжения сила отталкивания преодолевает поверхностное натяжение. Это приводит к образованию струи жидкости из конуса Тейлора. Если раствор не обладает достаточным когезионным притяжением, струи разрушаются, а образующиеся капли распыляются на коллектор (электрораспыление). При прохождении через воздух от конца капилляра к корпусу коллектора струи с высокой вязкостью, растворитель испаряется и на коллектор осаждается твердое волокно полимера.

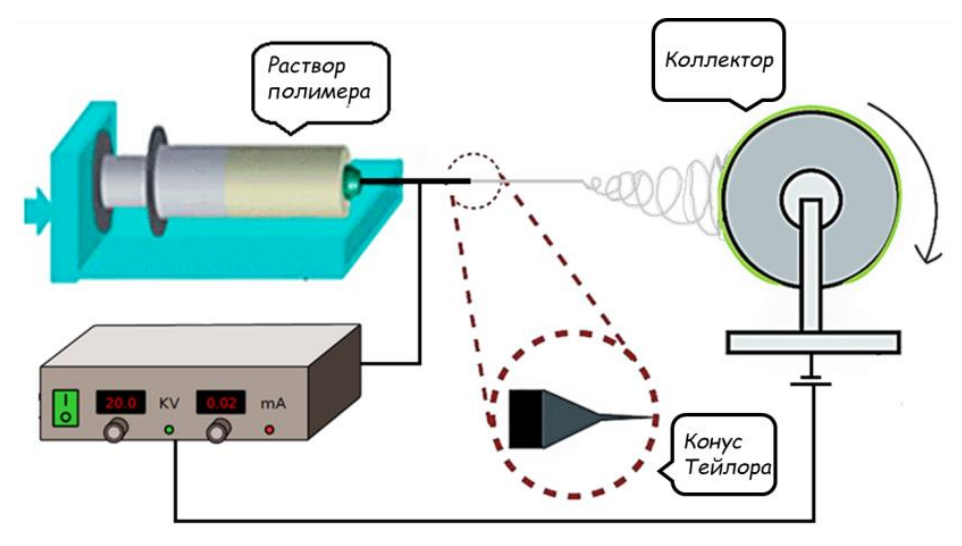

Pис.1. Установка для электроспиннинга

Технология электроспиннинга предоставляет широкий выбор материалов для создания и модификации полимерных матриксов, обеспечивающих высокую 
эффективность инкапсуляции биоактивных молекул и пригодных для биомедицинских приложений. На настоящий момент предложены разнообразные способы загрузки, отличающиеся по сложности реализации и эффективности в зависимости от природы используемых полимеров и вводимых агентов. Комбинируя различные подходы, можно создавать платформы, в той или иной степени обеспечивающие желаемые фармакокинетический и фармакодинамический профили препаратов, а также наделять такие системы доставки дополнительными функциями.

Системы контролируемой доставки на основе 3D-скаффолдов, полученных методом электроспиннинга

Полимерные нано- и микроволокна, полученные методом электроспиннинга, способны контролировать высвобождение нагруженных препаратов, регулируя скорость их диффузии. Следует отметить высокую эффективность инкапсуляции, стабильность, биосовместимость и биодеградируемость обсуждаемых материалов. Перспективы и проблемы применения нагруженных биоактивными агентами волокон подробно исследуются. На настоящее время определен ряд факторов, влияющих на морфологию волокон и их использование в системах контролируемой доставки [5]. Полимеры, параметры и тип электроспиннинга определяют кинетику выхода инкапсулированных агентов. В зависимости от профиля высвобождения, который необходимо обеспечить в тех или иных случаях, на основе полимерных волокон были разработаны различные системы контролируемой доставки (СКД), включая трансдермальные, быстрорастворимые, «интеллектуальные» и имплантируемые.

\section{Системы трансдермальной доставки}

Трансдермальные СКД - пластыреобразные лекарственные формы нового поколения, предназначенные для непрерывной подачи ЛС через неповрежденную кожу в системное кровообращение в течение длительного времени. Такие терапевтические системы обеспечивают высокую доступность препарата и могут доставлять его локально, обходя нежелательные метаболические пути (в том числе эффект первого пассажа) и длительно поддерживая концентрацию препарата на необходимом уровне.

В исследованиях сообщается о повышении растворимости препаратов биофармацевтической системы классификации II без увеличения их цитотоксичности и с сохранением высокой терапевтической эффективности, посредством включения их в состав трансдермального пластыря методом ЭС [6]. Авторы проанализировали проникновение ирбесартана ex vivo через кожу крысы и обнаружили, что по сравнению с полимерными пленками, 3D-скаффолды обеспечивают более высокую эффективность инкапсуляции (97\% против 78\%) и высвобождение препарата (89\% высвобождения за 4 ч против $71 \%$ за 8 ч). Выход препарата из пластыря осуществлялся в 2,5 раз быстрее, чем из пленки, что говорит о высокой проницаемости кожи для трансдермальных СКД и их перспективности для эффективной доставки препаратов.

Трансдермальные пластыри на основе полимерных волокон, обеспечивающие быструю кинетику высвобождения могут использоваться при лечении глубоких повреждений, увеличивая скорость регенерации и уменьшая боль. Так, Kataria и соавт. создали трансдермальные пластыри из нагруженных индометацином поливинилпирролидоновых волокон с эффективностью инкапсуляции $75 \%$ и полностью высвобождающие препарат через 45 мин [7]. Следует отметить, что в последние годы большая часть полимерных скаффолдов нагруженных ЛС, используется именно в виде трансдермальных СКД.

\section{Быстрорастворимые системы доставки}

Данные терапевтические системы представляют собой тонкие пленки, размещаемые на слизистой оболочке полости рта и в процессе растворения высвобождающие активные компоненты. Быстрорастворимые СКД привлекают большой интерес фармацевтических компаний, поскольку увеличивают биодоступность препарата и обеспечивают его быстрое растворение во рту без воды, а 
высокая проницаемость слизистой оболочки полости рта ускоряет поступление ЛС непосредственно в кровоток, минуя агрессивную среду желудка и ферментные системы печени. При помощи электроспиннинга из гидрофильных полимеров (хитозан, ПВС, полиакриламид) была получена сублингвальная система для доставки суматриптан сукцината и напроксена в течении 10 минут (90\% от нагруженного количества) [8]. Potrc и соавт. использовали скаффолд из поликапролактона и плохо растворимого в воде ибупрофена или карведилола для разработки оромукозной системы доставки [9].

\section{«Интеллектуальные» системы доставки}

«Интеллектуальные» СКД, модулирующие скорость высвобождения ЛС в зависимости от окружающих условий ( $\mathrm{pH}$, температура, магнитное поле, осмотическое давление), стали развиваться относительно недавно. Такие системы создаются в виде гидрогелей (ионных, кислых или основных, с акцепторами электронов, с иммобилизованными ферментами), полиэлектролитных гелей (реагирующих на электрическое поле), гелей на основе этиленвинилового спирта (нагревающихся под действием ультразвука), магнитных частиц, а также рН- и термочувствительных волокон. Чаще всего используются рН-зависимые полимеры, нановолокна из которых деформируются («набухают») либо начинают активнее деградировать при соответствующих значениях $\mathrm{pH}$.

Так, исследования показали, что нагруженные будесонидом скаффолды из полимера Eudragit в кислых условиях препятствуют выходу препарата и демонстрируют профиль его замедленного высвобождения при $\mathrm{pH}>7$. Такие материалы перспективны для лечения кишечных заболеваний с помощью противовоспалительных препаратов. Интересны также температурно-зависимые полимеры (например, поли-Nизопропилакриламид), которые меняют свойства с гидрофильных на гидрофобные при повышении температуры и могут использоваться для термочувствительной доставки $[10,11]$.

Нагруженные волокна часто демонстрируют двухфазную кинетику высвобождения, включая начальный быстрый выход препарата, необходимый для немедленного эффекта, и последующую фазу пролонгированного высвобождения для поддержания нужной концентрации. Как правило, основная часть («ядро») волокон для замедленного высвобождения представлено гидрофобными полимерами, в то время как «оболочка» для быстрого высвобождения создается на основе гидрофильных полимеров. Так, зеин и ПВП использовались для получения нагруженных низкорастворимым кетопрофеном волокон, обеспечивающих 42,3\% выхода в начале и длительное высвобождение препарата в течение следующих 10 ч [12]. Сообщается, что матрикс, внешние слои которого состоят из гидрофильного полимера, а средняя часть из гидрофобного полимера, демонстрирует двухфазную кинетику высвобождения препаратов в течение 24 ч (начальный выход 45\%) [13]. Lee и соавт. получили зеиновые волокна для внешних слоев и ПВП-волокна, нагруженные частицами оксида графена, в качестве среднего слоя для создания трехслойных матриц, высвобождающих кетопрофен. Гидрофильные полимеры обеспечили выход $60 \%$ препарата за 2 ч, а гидрофобный полимер пролонгировал выход оставшегося в течение следующих 15 ч [14]. Изменяя толщину каждого слоя можно регулировать время высвобождения препарата на соответствующей стадии. Многослойные материалы из полимерных нановолокон предложили новый идеи не только для достижения двухфазного, но и многофазного высвобождения лекарственных препаратов.

\section{Имплантируемые системы доставки}

Имплантируемые СКД используются при хронических заболеваниях, когда требуется длительный и сложный график приёма ЛС. Такие системы обычно создаются в виде имплантируемых насосов (например, для внутривенной или внутрибрюшинной инфузии раствора инсулина), представляющих из себя несложные устройства в форме 
резервуаров, которые нуждаются в периодической заправке препаратом (в основном, чрескожно). Нагруженные биоактивными агентами имплантаты на основе биодеградируемых 3D-матриксов, полученных методом ЭС, имеют преимущества в виде имплантируемых систем, обеспечивая пролонгированную и таргетную доставку и не требуя регулярное пополнение препаратом.

Так, полиангидридные диски, нагруженные кармустином, были имплантированы в мозг кроликов на поверхность участка резекции глиомы и обеспечили замедленное высвобождение препарата в течении трех недель, что вызвало разрушение оставшихся тканей опухоли [15]. Хu и соавт. инкапсулировали доксорубицин в волокна из поли-L-лактида и исследовали их эффективность для локальной химиотерапии против вторичной карциномы печени, имплантировав матрицу вблизи опухоли [16]. Выход препарата был осуществлен за 24 часа с дальнейшей локализаций преимущественно в печени; в результате рост опухоли был значимо ингибирован, а среднее время выживания мышей увеличилось. Аналогичные результаты продемонстрировали Luо и соавт., получив коаксиальные волокна с ядром, содержащим гидроксикамптотецин и гидроксипропилциклодекстрин [17].

Важно отметить, что в биомедицинской практике имплантируемые полимерные скаффолды применяются не только в качестве «резервуаров» содержащих ЛС, но и непосредственно служат каркасом для регенерации поврежденной ткани, усиливая миграцию, пролиферацию и дифференцировку клеток благодаря своей ультраструктуре. В частности, исследования демонстрируют, что полимерные волокна, нагруженные остеогенными факторами и имплантируемые в зону травмы кости, улучшают ее регенерацию. Так, Zhu и соавт. создали волокна, состоящие из PEG (ядро) и PCL (оболочка) в качестве носителя для BMP-2. Полученные матрицы обеспечили ускоренное заживление кости in vivo на модели дефекта черепа кролика [18].

Кроме того, возможность в процессе электроспиннинга ориентировать полимерные волокна строго параллельно друг другу (для этого используется модифицированный коллектор с мельчайшими встроенными электродами) имеет важное значение для инженерии нервной ткани. Wang и соавт. включили фактор роста нервов в выровненные волокна, полученные методом коаксиального электроспиннинга. Скаффолды были имплантированы в область поврежденного седалищного нерва крыс. В результате, физико-механическое влияние выровненных волокон в комплексе с биохимическими сигналами значительно улучшило регенерацию нервной ткани [19].

Широкое применение полимерных 3D-скаффолдов, получаемых методом электроспиннинга, находит место в регенеративной медицине при изготовлении протезов сосудов и биосовместимых сосудистых стентов. В этой отрасли полимерные графты применяются в качестве имплантируемых систем доставки лекарств либо непосредственно, либо в качестве покрытия. Lee и соавт. создали PLGA-скаффолды для локальной доставки эпигаллокатехин-3-О-галлата для уменьшения гиперплазии интимы в поврежденной брюшной аорте. Исследования in vivo показали ингибирование развития гиперплазии на поврежденном участке сосуда с имплантированным каркасом, нагруженным препаратом, по сравнению с обычным полимерным графтом [20].

Таким образом, технология электроспиннинга позволяет обеспечить устойчивое пролонгированное высвобождение биомолекул из полимерных 3D-материалов, что в комбинации с пористой микроструктурой каркаса создает благоприятную среду для прикрепления, миграции и пролиферации клеток, опосредуя регенерацию тканей. Кроме того, метод электроспиннинга позволяет создавать гибридные платформы, 
структурированные с наноносителями, использующимися для доставки биохимических агентов. Учитывая все преимущества, очевидно, что технологии элетроспиннинга обладают большим потенциалом для создания систем контролиуемой доставки биоактивных агентов и регенеративной медицины.

$* * *$

1. Okuda T., Tominaga K., Kidoaki S. Time-programmed dual release formulation by multilayered drugloaded nanofiber meshes // J. Control. Release. Elsevier B.V., 2010. Vol. 143, № 2. P. 258-264.

2. Ren X. et al. An aligned porous electrospun fibrous membrane with controlled drug delivery - An efficient strategy to accelerate diabetic wound healing with improved angiogenesis // Acta Biomater. 2018. Vol. 70. P. 140-153.

3. Tort S. et al. Development and characterization of rapid dissolving ornidazole loaded PVP electrospun fibers // Pharm. Dev. Technol. Taylor \& Francis, 2019. Vol. 24, № 7. P. 864-873.

4. Riggin C.N. et al. Electrospun PLGA Nanofiber Scaffolds Release Ibuprofen Faster and Degrade Slower After In Vivo Implantation // Ann. Biomed. Eng. 2017. Vol. 45, № 10. P. 2348-2359.

5. Balogh A. et al. Plasticized drug-loaded melt electrospun polymer mats: Characterization, thermal degradation, and release kinetics // J. Pharm. Sci. 2014. Vol. 103, № 4. P. 1278-1287.

6. Kamble R.N. et al. Fabrication of electrospun nanofibres of BCS II drug for enhanced dissolution and permeation across skin // J. Adv. Res. Cairo University, 2016. Vol. 7, № 3. P. 483-489.

7. Kataria K. et al. In vivo wound healing performance of drug loaded electrospun composite nanofibers transdermal patch // Int. J. Pharm. Elsevier B.V., 2014. Vol. 469, № 1. P. 102-110.

8. Vrbata P. et al. Electrospun drug loaded membranes for sublingual administration of sumatriptan and naproxen // Int. J. Pharm. Elsevier B.V., 2013. Vol. 457, № 1. P. 168-176.

9. Potrč T. et al. Electrospun polycaprolactone nanofibers as a potential oromucosal delivery system for poorly water-soluble drugs // Eur. J. Pharm. Sci. 2015. Vol. 75. P. 101-113.

10. Wei Z. et al. Novel PNIPAm-based electrospun nanofibres used directly as a drug carrier for "on-off" switchable drug release // Colloids Surfaces B Biointerfaces. Elsevier, 2019. Vol. 182, № July. P. 110347.

11. Wei Z. et al. Fabrication of novel dual thermo- and $\mathrm{pH}$-sensitive poly (N-isopropylacrylamide-Nmethylolacrylamide-acrylic acid) electrospun ultrafine fibres for controlled drug release // Mater. Sci. Eng. C. Elsevier, 2020. Vol. 115, № January. P. 111050.

12. Jiang Y.N., Mo H.Y., Yu D.G. Electrospun drug-loaded core-sheath PVP/zein nanofibers for biphasic drug release // Int. J. Pharm. Elsevier B.V., 2012. Vol. 438, № 1-2. P. 232-239.

13. Huang L.Y. et al. Time-engineeringed biphasic drug release by electrospun nanofiber meshes // Int. J. Pharm. Elsevier B.V., 2012. Vol. 436, № 1-2. P. 88-96.

14. Lee H. et al. Electrospun tri-layered zein/PVP-GO/zein nanofiber mats for providing biphasic drug release profiles // Int. J. Pharm. Elsevier, 2017. Vol. 531, № 1. P. 101-107.

15. Domb A.J. et al. Excretion of a radiolabelled anticancer biodegradable polymeric implant from the rabbit brain // Biomaterials. 1995. Vol. 16, № 14. P. 1069-1072.

16. $\mathrm{Xu} \mathrm{X}$. et al. The release behavior of doxorubicin hydrochloride from medicated fibers prepared by emulsion-electrospinning // Eur. J. Pharm. Biopharm. 2008. Vol. 70, № 1. P. 165-170.

17. Luo $\mathrm{X}$. et al. Antitumor activities of emulsion electrospun fibers with core loading of hydroxycamptothecin via intratumoral implantation // Int. J. Pharm. Elsevier B.V., 2012. Vol. 425, № 12. P. $19-28$.

18. Zhu H. et al. Biological activity of a nanofibrous barrier membrane containing bone morphogenetic protein formed by core-shell electrospinning as a sustained delivery vehicle // J. Biomed. Mater. Res. Part B Appl. Biomater. 2013. Vol. 101, № 4. P. 541-552.

19. Wang C.Y. et al. The effect of aligned core-shell nanofibres delivering NGF on the promotion of sciatic nerve regeneration // J. Biomater. Sci. Polym. Ed. 2012. Vol. 23, № 1-4. P. 167-184.

20. Lee M.H. et al. Exovascular application of epigallocatechin-3-O-gallate-releasing electrospun poly(1lactide glycolic acid) fiber sheets to reduce intimal hyperplasia in injured abdominal aorta // Biomed. Mater. IOP Publishing, 2015. Vol. 10, № 5. P. 55010. 